\title{
OS CAMINHOS DA MEMÓRIA EM MOMENTS OF BEING
}

\author{
Patricia Marouvo Fagundes \\ Doutoranda em Literatura Comparada (UFRJ) \\ patriciamarouvo@yahoo.com.br
}

\section{RESUMO}

Em suas memórias, reunidas no volume Moments of Being (1972), Virginia Woolf se imbui da tarefa representativa de acompanhar o fluxo da vida, escrevendo sobre momentos de sua infância, cuja densidade causaram tamanha impressão que, ainda na idade adulta, a autora se vê convocada a redimensionar a medida em que as lembranças do passado pressionam a maneira de compreensão do presente. Sua escrita a convoca a uma resposta, estimulada pela motivação racional em ver-se capaz de, simbolicamente, apresentar os baques da vida, reassimilados no processo de escritura para sobreviver ao impacto e saciar um desejo de revelação do indício de algo real por trás das aparências, que se torna real ao ser colocado em palavras. Pretende-se aqui pensar suas memórias a partir de questões que se mostram cruciais e recorrentes em sua poética, almejando desenvolver sua relevância no processo de escrita e na elaboração da tensão entre identidade e consciência.

Palavras-chave: memória; representação; subjetividade.

\section{ABSTRACT}

In her memoirs, collected in the volume Moments of Being (1972), Virginia Woolf sets herself the task of representation in following the thread of life when writing about moments of her childhood that still have an impact on her in late adulthood, given their paramount importance. Such moments make an impression on the way the present moment can be comprehended, and so in writing the author responds to the stimuli that she is now symbolically able to reassess to survive the impact of such experiences and satiate the desire for the revelation of something that lingers behind appearances and becomes even more real when put into words. The aim of this article is to reflect on her memoirs, considering the fundamental issues that are elaborated in her oeuvre, and to expand on their relevance in the process of writing and the tension established between identity and conscience.

Keywords: memory; representation; subjectivity. 
Em suas memórias, que mais tarde seriam reunidas no volume Moments of Being (1972), Virginia Woolf se imbui da tarefa representativa de acompanhar o fluxo da vida, escrevendo sobre momentos de sua infância, cuja densidade causaram tamanha impressão que, ainda na idade adulta, a autora se vê convocada, inúmeras vezes, a redimensionar a medida em que as lembranças do passado pressionam a maneira de compreensão do presente. Se, primeiramente, sua metodologia se mostra incerta, mais tarde se modela como uma procura, uma aprendizagem da presença concreta de um passado cronologicamente ausente, mas inevitavelmente incrustado no momento presente, evolando, com a sutileza de um sussurro em nossos ouvidos, um chamado para uma escuta atenciosa do impulso de vida que nos move.

Afirma ainda que essa procura revela-se tão mais árdua por causa da minuciosa dificuldade de descrever o ser humano e de separá-lo dos outros, em sua propriedade. Como discernir a influência do pai, o grande patriarca que tanto a influenciou em seus estudos filosóficos, historiográficos e biográficos? Da mãe, a figura amável, ainda que rígida, responsável pela estabildade e pela felicidade familiar? E dos irmãos ou primos e tias? - se perguntava Virginia em 1939. O esforço da escrita sempre a sobreveio como apelo, necessidade de reunião dos diferentes pontos de referência de sua rede primária, sua família. Declara que a capacidade de sobreviver aos choques externos é que a transformou em uma escritora. A escrita forçosamente a convoca a uma resposta, estimulada pela motivação racional em se ver capaz de, simbolicamente, apresentar os baques da vida, reassimilados no processo de escritura a fim de sobreviver ao impacto e saciar um desejo de 
revelação do indício de algo real por trás das aparências, que se torna real ao ser colocado em palavras (WOOLF, 1985).

Suas lembranças são tingidas pelas cores de um passado difuso, mas pontuado por momentos precisos porque decisivos. Elas, por uma impossibilidade representativa, jamais conseguiriam ser acessadas diretamente, num contato puro e unidirecional, ao encontro do passado em si mesmo. As memórias tecidas acerca da família Stephen são revisitadas e reformuladas pelo olhar da já madura e experiente Virginia Woolf, sendo delineadas pela maneira como o presente filtra, analisa e reconfigura o que ainda resta e afeta a autora no momento em que registra suas impressões. O escritor de memórias deve estar ciente da dimensão ôntica de suas lembranças quando representadas em um dado suporte material. Isso porque sua lembrança reelabora o que, de fato, foi vivido, tendo à sua disposição as diferentes configurações de formulação pela língua e, além disso, os caminhos de sentido que podem ser perseguidos, deliberadamente ou não (GONÇALVES, 2014).

Inúmeras limitações e decisões estão em jogo na seleção linguística, micro ou macroestruturalmente. Seja na seleção vocabular ou nas estruturas sintáticas, ritmadas pela musicalidade sonorizada pelos temas e situações, as escolhas, conscientes ou não, ajudarão a moldar os momentos passados, na medida em que o próprio tom dos eventos sugere e delimita as opções à disponibilidade. E dos fatos ocorridos em um passado distante, só nos restam as lembranças, essas sim concretas e passíveis de assimilação, pois nada mais são senão nossa interpretação do que passou. O passado em si é tão intangível e distante quanto o futuro, feito de previsões e suposições, que, na verdade, simplesmente apontam nossos receios e desejos presentes. Desse modo, deve-se atentar também ao momento de 
enunciação. É a partir do momento presente que novas lembranças e interpretações são tecidas nas novas redes de sentido que se configuram como possibilidade pela ótica no momento de escritura, mostrando que o passado não é estável ou impermeável (GONÇALVES, 2014).

Essa dimensão ôntica de escritura se revela tão mais rica quanto mais abertos estamos às suas próprias limitações. As lembranças, enquanto resquícios de um passado atualizado porque reinterpretado pela ótica presente, podem obnublar seu potencial transformador se compreendidas à luz de uma mera representação cujo produto final se consumaria em uma finalidade, um estágio último atravessado pela esperança utilitária de conhecer-se a si mesmo como sujeito portador de uma identidade definida. Na dobra que reúne ser e ente, a lembrança, sendo, se atualiza no vigor da memória, apontando para sua própria limitação, seu recorte representacional e, por isso, simbólico do todo de que faz parte. As lembranças, sempre de forma ensaística, devem, em última instância, redimensionar o silêncio sugerido pelo apelo de algo maior, algo embrionário, na comunhão das restrições que o inominável manifesta sem permitir a clara denominação, sem permitir o uso de uma palavra que conforme e confirme presença frente à existência humana.

Virginia Woolf encara esse empreendimento, isto é, o manuscrito que mais tarde originaria Moments of Being, de maneira despretensiosa, mas simultaneamente esclarecedora. Sua liberdade é pautada na falta de caminhos previamente planejados, porque sua ambição se consuma como exercício de reflexão, cujo objetivo máximo visa à contemplação da possibilidade de habitar sua identidade, unindo as duas pontas da vida. Inicia seu método com perguntas, como: qual é minha primeira memória? E como ela ajuda 
a delimitar o indivíduo que sou? Minha família também faz parte de minha identidade? Até que ponto posso dizer que eu não sou o outro? Obviamente, qualquer leitor mais atento pode divisar o descortinar diáfano de um caminho errante; errante, porém, para chegar ao lugar de origem de travessia das veredas limítrofes entre vida e morte, vida plenificada e impulsionada pela morte, por se dar na morada do ser.

Em Moments of Being, é desenvolvida a filosofia que atua como fio condutor das obras literárias de Virginia Woolf, do início ao fim de sua carreira. Revisitadas em diversos momentos de sua escrita, as questões situadas nos limites da existência e da performance, entre vida e morte, dão corpo a uma filosofia contemplativa e intuitiva acerca da textura da realidade e as condições de possibilidade para nomeá-la. O momento de percepção, nem sempre seguido do momento de compreensão, instala, pelo desespero ou pela satisfação, a densidade velada por um cotidiano banal. O momento de vida, sendo, ganha peso e sentido quando marcado pela intensidade limítrofe entre ser e não-ser, entre perceber e compreender.

Com apenas três exemplos, dois de desespero e um de plena satisfação, Virginia remonta aos momentos em que sente as forças de vida e de morte percorrerem sua infância. Recorda-se vividamente do embate físico com seu irmão Thoby com quem troca golpes até o momento fatal em que percebe a fúria pela qual é tomada e que a incita a machucar até mesmo aqueles que mais ama, revelando a brutalidade inerente ao ser humano. Também na infância, ela se lembra da notícia entreouvida do suicídio de um amigo da família Stephen, e o quão forte foi a crise produzida ao entrever o peso dessa decisão última que, inevitavelmente, para Virginia, seria associado à macieira do jardim de sua casa, 
símbolo do grande pecado cristão, tão ameaçador à estruturação rígida e, por isso mesmo, confiável da sociedade vitoriana no século XIX. Diferentemente das duas cenas anteriores, o último fragmento apresentado pela autora introduz a possibilidade de aprendizagem na alegria de descobrir a complexidade da realidade num canteiro de flores, simultaneamente analisando-o e percebendo a si mesma como parte da vida maior que também a engloba.

Essas breves cenas indicam a possibilidade de marcar o passado através de imagens: "uma cena sempre vem à superfície, ordenada, representativa" (WOOLF, 1985, p. 142). Inserida na tradição platônica, a literatura woolfiana sinaliza a força das imagens poéticas ao suscitarem questões que coadunam claridade e obscuridade, reunidas na tensão entre ser, não ser e dissimular. Uma imagem impulsiona o questionamento quanto mais tem o poder de desdobrar a realidade em sua complexidade, permitindo que a obscuridade do oculto se insinue sob o véu que, por instantes fugazes, desvelam a luz com que, pela linguagem, possibilita discernir o que se nos apresenta, ainda que para isso não haja palavras que, racionalmente, signifiquem a relação entre corpos. A ideia representada pela cena jaz no limite entre dizer e não-dizer, revelar e ocultar, insinuar obliquamente o inominável, a que intuitivamente nos recordamos pertencer enquanto doação do silêncio no seio da linguagem.

Dialogando com o ensaio “... poeticamente o homem habita..." de Martin Heidegger, podemos pensar a relevância da imagem poética quando entendida como imaginação, ou melhor, "imaginações e não meras fantasias ou ilusões. Imaginações entendidas não apenas como inclusões do estranho na fisionomia do que é familiar mas também como inclusões passíveis de serem visualizadas" (HEIDEGGER, 2010, p. 177). A imaginação permite ver o

\footnotetext{
${ }^{1}$ A scene always comes to the top; arranged; representative. Todas as traduções são de minha autoria.
} 
estranho no familiar, mesclando a claridade daquilo que, conhecendo, podemos reconhecer e a obscuridade daquilo que, se insinuando, podemos intuir como possibilidade ofertada pela linguagem. "O dizer poético das imagens reúne integrando a claridade e ressonância dos muitos aparecimentos celestes numa unidade com a obscuridade e a silenciosidade do estranho" (HEIDEGGER, 2010, p. 177).

As imagens deixam entrever alguma coisa. Elas dizem o nominável, marcando, pela memória, o sentimento ocasionado pelo evento representado. A marca dessas imagens passa a integrar o conjunto de momentos disponíveis à rememoração das partes de um todo que compõem uma vida, por terem sido incorporadas e, assim, representarem o todo que um indivíduo é. Por outro lado, o inominável é sugerido no vigor de realização representativa do que a língua não consegue acessar, silenciando e, paradoxalmente, potencializando as possibilidades ofertadas pela linguagem. Estranhamos a familiaridade de algo que ainda não conhecemos, mas cujo eco ressoa nos labirintos do espírito por acordar o que estava adormecido, e cuja existência sequer podíamos imaginar. Imaginamos o inominável a partir de nomes e, assim, fabricamos a textura de uma realidade visualizável e passível somente de reconhecimento intuitivo nos instantes em que abraçamos o que Gaston Bachelard (2009) alcunha de "devaneio poético".

Acometidos pelo devaneio poético, poetas e demais artistas comungam de uma sensibilidade exercitada ao longo de anos, operando diferentes mundos em suas obras e, consequentemente, atingindo um amplo público por conseguir ressoar os desdobramentos da realidade maior, que todos compartilhamos. Bachelard assinala "que o devaneio nos dá o mundo de uma alma, que uma imagem poética testemunha uma alma que descobre o seu 
mundo, o mundo onde ela gostaria de viver, onde ela é digna de viver" (BACHELARD, 2009, p. 15). A tangibilidade do diálogo entre as vozes que soam numa obra literária e a do leitor provoca e convoca um diálogo com a alteridade do outro e a que jaz em nós mesmos. A poética do texto promove uma abertura que "dá ao eu um não-eu que é o bem do eu: o não eu meu" (BACHELARD, 2009, p. 13). Encantamo-nos com os recessos do espírito do poeta por também já repercutirem no nosso numa relação especular que adentra os labirintos do (in)consciente de um sujeito pensante, sendo a leitura a experiência necessária para ativar esse maravilhamento adormecido e entorpecido em nossas rotinas dessensibilizadas.

A tríade ligação memória, imaginação e poesia aponta para a natureza do devaneio poético. É preciso alargar os limites da própria coragem para experienciar a liberdade larga de sonhar as próprias lembranças. "Sonhamos enquanto nos lembramos. Lembramo-nos enquanto sonhamos" (BACHELARD, 2009, p. 96). Somente assim podemos reinterpretar o passado atualizado em presente e potencializado como futuro. O fazer poético desperta em nós "um novo estado de infância, de uma infância que vai mais longe do que as lembranças de nossa infância que ficou inconclusa e que, no entanto, era nossa e que, sem dúvida, por diversas vezes temos sonhado" (BACHELARD, 2009, p. 100). Ativar fragmentos permeados por uma profusão de sinestesias pode se tornar tarefa infinita para um adulto racional. Por outro lado, para a criança nada é mais libertador do que se perder em sua própria solidão criativa, simultaneamente acolhida pela alegria de ser cuidada pela mão segura do pai ou o colo quente da mãe. Algo tão simples como os cheiros e perfumes da casa em que se morava, uma melodia constante e ritmada, cores realçadas pelo brilho e o calor do sol 
ajudam a registrar momentos que remontam uma história de família com seus amores e pesares, felicidades e traumas.

A consonância de um mesmo sentimento sob diferentes representações mostra o traço ancestral de uma memória compartilhada entre escritores e leitores. Meditando sobre a criança que fomos, ultrapassamos as limitações do álbum de família e, após as miragens de nostalgia haverem dispersado, atingimos "uma infância anônima, puro foco de vida, vida primeira, vida humana primeira" (BACHELARD, 2009, p. 120). Esse potencial de infância compartilhada, ou melhor, esse arquétipo ${ }^{2}$ da infância se torna, então, tão mais poderoso ao reviver os grandes arquétipos das potências paternas e maternas. Estes ajudam a construir uma rede primária que, simbolica e afetuosamente, alicerça as bases para o cutivo intelectual e emocional de uma vida, sustentando a crença na confiabilidade da permanência de outros pontos de referência e estabelecendo uma ordenação própria frente ao caos anteriormente absoluto. A partir do estabelecimento desses laços afetivos, podemos explorar o mundo entorno, amparados com segurança do mundo constituído por fluxos selvagens (LIMA, 2002).

O mundo da infância da jovem Virginia vigora no mundo habitado por Virginia Woolf. Nos seus devaneios mais solitários e, por isso, mais livres de pressões externas, a escritora trabalha a dinâmica de perda e preservação dos fluxos do passado familiar, ancorados nas figuras centrais do pai e da mãe. Voltada para sua infância, ela descortina as possibilidades de reinterpretação e reconhecimento de questões que parecem nos apresentar "um ser

\footnotetext{
${ }^{2} \mathrm{O}$ conceito de arquétipo não deve ser entendido aqui como uma generalização abstrata, que inevitavelmente não poderia abarcar a complexidade da realidade empírica de que tratamos, ou seja, as memórias de Virginia Woolf. Melhor seria compreendê-lo à luz da comunhão do potencial que as questões humanas têm em comum, pretendendo, assim, somente apontar horizontes de interpretação de um momento que perdura.
} 
anterior ao nosso ser, toda uma perspectiva de antecedência do ser" (BACHELARD, 2009, p. 103). Essas questões voltam a sugerir na penumbra de uma realidade difusa, fabricada entre a imaginação e a rememoração, a insistente possibilidade de estados ainda em movimento de vir a ser, que ainda não sendo, somente figuram como potencialidades. Leitores são, assim, confrontados com a familiaridade compartilhada a partir de histórias da infância alheia, tão sua quanto do outro por serem todas elas tecidas pelo mesmo fio condutor, uma vida profunda relacionada à "possibilidade de recomeçar" (BACHELARD, 2009, p. 119). O sonho imagina os descaminhos que o destino disponibilizou, mas não fez cumprir. A imaginação sonha o que foi realizado, redimensionando as leituras das leituras do passado. Nesse entre imaginar e sonhar, as memórias escritas desenham o curso de uma vida que se faz no processo de escritura e de leitura, ciclicamente se renovando pelo devaneio artístico.

Nesse momento oportuno, somos perpassados por aquilo que mais tarde Virginia Woolf chamaria de moments of being, isto é, momentos em que o contato com a realidade assume sentido e peso em sua história de vida, por se darem na intimidade reveladora em que o ser humano se consuma em sua propriedade ainda que somente por um instante. A partir de um grande choque, suas convicções e até mesmo banalizações são inevitavelmente redimensionadas, pois uma nova janela de compreensão foi aberta, descerrando diferentes modalidades de re-conhecimento do real. Esse moment of being, esse momento em que se é, momento do ser, mostra a dinâmica de desdobramento do ser, vigorando sempre no ente e, por isso, pertencendo um ao outro. $\mathrm{O}$ afastamento do entendimento tradicional do duplo nos remete, assim, para a dimensão da dobra, que não aprecia ser e ente como opostos 
antagônicos ou mesmo complementares, mas como um todo que, na língua portuguesa, poderia ser melhor traduzido pela palavra sendo.

O moment of being deixa de lado o estado generalizado de non-being em que funcionamos necessária e frequentemente. Seja ao caminhar, comer, ver as coisas, lidar com o que deve ser feito, como o aspirador de pó quebrado, o almoço a ser encomendado, escrever as ordens do dia para Mabel, ou lavar, fazer o jantar e encadernar livros (WOOLF, 1985). As atividades rotineiras são realizadas automaticamente e sem muita reflexão por demandarem pouca apreciação do extraordinário que se anuncia e revela o que antes, aos nossos olhos, permanecia enconberto. Podemos dizer que no moment of non-being já está a possibilidade de algo mais significativo, de que o moment of being possa vir à tona, alargando nossa percepção de um tempo que perdura na memória e ajuda a sedimentar os alicerces de uma vida. Esse moment of being é, por natureza, fugidio e, desse modo, é acompanhado de sucessivas instâncias de non-being, ciclicamente se renovando e permitindo vislumbrar sentido em sua densidade, enconberto pelo hábito de um cotidiano banal.

“Este é o todo" ${ }^{3}$ (WOOLF, 1985, p. 71), percebia Virginia ao se deparar com o canteiro de flores. Ainda muito jovem para poder organizar linguisticamente o que a acometia, ela podia entender a densidade da imagem na consonância de energias que dela e das flores emanavam, comungando a reciprocidade espelhada entre o mesmo que une diferentes. 0 todo pode ser visualizado e melhor compreendido à medida que as partes são reunidas pela tessitura de cenas, dos choques que fazem um apelo a ser respondido no processo de escritura. A dinâmica circular da sucessão de repentinos golpes, seguidos da sede por

${ }^{3}$ This is the whole. 
compreensão, conforma o eterno devir daqueles que procuram dar sentido às duas forças maiores a que estamos sujeitos: a vida e a morte.

Ordenando com palavras uma filosofia intuitiva, Virginia já adulta buscava visualizar o padrão. Esse padrão, no entanto, não se configura como um sistema pré-definido, admitindo apenas categorias unas que engessariam qualquer tipo de movimento para além das suas classificações. Esse padrão, na verdade, revela uma harmonia na confluência de energias que possibilitam que tudo aquilo que já é permaneça em seu elemento propriamente, a partir de uma mobilidade viva que enseja atualização frente às diferentes circunstâncias.

A partir disso, alcanço o que poderia ser chamado de uma filosofia; de todo modo, é uma ideia minha constante; que por trás do algodão está escondido um padrão; que nós - quero dizer todos os seres humanos - estamos conectados a isso; que o mundo é uma obra de arte; que nós somos partes dessa obra de arte. Hamlet ou um quarteto de Beethoven é a verdade sobre esta grande massa que chamamos de mundo. Mas não há Shakespeare, não há Beethoven; certa e enfaticamente não há Deus; somos as palavras; somos a música; somos a coisa em si mesma. E vejo isso quando tenho um choque ${ }^{4}$ (WOOLF, 1985, p. 72).

Esse padrão subjacente ao mundo conecta todos os seres humanos que, poeticamente passam a habitar sua própria humanidade. Em conexão máxima consigo mesmo, o ser humano autenticamente opera mundo, escrevendo, musicando, pintando, atuando ou

${ }^{4}$ From this I reach what I might call a philosophy; at any rate it is a constant idea of mine; that behind the cotton wool is hidden a pattern; that we - I mean all human beings - are connected with this; that the world is a work of art; that we are parts of the work of art. Hamlet or a Beethoven quartet is the truth about this vast mass we call the world. But there is no Shakespeare, there is no Beethoven; certainly and emphatically there is no God; we are the words; we are the music; we are the thing itself. And I see this when I have a shock. 
dançando, ou seja, corresponde ao que lhe compete, sendo, no seu agir próprio ao dialogar, respondendo aos apelos da linguagem. O homem se essencializa sabendo-se mortal e, por isso, "capaz da morte como morte. Somente o homem morre - e, na verdade, continuamente, enquanto se demora sobre esta terra, enquanto habita. Seu habitar se sustenta, porém, no poético" (HEIDEGGER, 2010, p. 173). Seu agir é histórico porque faz do tempo instantes ordenados pela memória, podendo, desse modo, discernir um antes e um depois, um momento singular e seus desdobramentos, todos estes rememorados, isto é, reunidos no seio amalgamador da memória.

As memórias póstumas de Virginia Woolf dão o tom do desespero da guerra, a todo vapor em 1940, freado pela necessidade de produzir algo vivo, que, dando conta do todo, fizesse o sentido do agir humano vir à tona, como a forma de protesto mais calorosa a que um escritor pode almejar. Suas palavras reconstroem o caminho de libertação de uma jovem escritora, ainda no auge da era vitoriana, rumo a uma apropriação do lugar que desejava conquistar como intelectual e como mulher no século XX. Sua voz, afirmando vida frente à morte dessensibilizada e generalizada, construiu um legado que, não só à sua época, mas também ainda no século XXI, permite que seus leitores divisem humanidade em face dos horrores do humano inumano.

\section{REFERÊNCIAS}

BACHELARD, Gaston. A poética do devaneio. São Paulo: Martins Fontes, 2009.

GONÇALVES, Adriana de Souza Jordão. Do imaginário à narrativa: a memória da casa de infância. Tese (Doutorado em Literatura Comparada) - Universidade do Estado do Rio de Janeiro, 2014. 
HEIDEGGER, Martin. “...poeticamente o homem habita...”. In: Ensaios e conferências. Petrópolis: Editora Vozes, 2010, p. 165-181.

LIMA, Vera. Herança e homenagem em Virginia Woolf. Tese (Doutorado em Ciência da Literatura) - Universidade Federal do Rio de Janeiro, 2002.

WOOLF, Virginia. Moments of Being. New York: Harcourt Inc, 1985.

Artigo recebido em: 13 de julho de 2018. Artigo aprovado em: 04 de agosto de 2018. 